\title{
Prognostic value of ocular trauma score for open globe injuries associated with metallic intraocular foreign bodies
}

\author{
Dilek Yaşa*'(D), Zeynep Gizem Erdem, Ali Demircan, Gökhan Demir and Zeynep Alkın
}

\begin{abstract}
Background: The prognostic value of the ocular trauma score (OTS) in patients who underwent 23-gauge pars plana vitrectomy (23-G PPV) for surgical removal of posterior segment metallic intaocular foreign bodies (IOFB) was evaluated.

Methods: Patients who underwent 23-G PPV for surgical removal of retained metallic IOFBs were retrospectively analyzed. OTS score for each patient was calculated and raw scores were converted to their corresponding OTS categories. The final VAs in study patients were compared with their respective OTS categories.

Results: Twenty-five eyes from 25 patients were examined. Twenty-four (96\%) of the patients were male, and the mean age was $34 \pm 12$ years. The time from injury to 23-G PPV was $9 \pm 4$ days. Fourteen (56\%) patients had zone 1 trauma, eight (32\%) patients had zone 2 trauma, and three (12\%) patients had zone 3 trauma. Postoperative visual acuity was $\geq 20 / 200$ in 14 (56\%) of the patients and $\geq 20 / 40$ in seven (28\%) eyes. At the final visit, anatomical success was achieved in $86 \%$ of patients with retinal detachment at presentation. No statistically significant differences were found between our final VAs and OTS scores.

Conclusion: OTS, which provides prognostic information after general ocular trauma, may also provide valuable prognostic information for patients who undergo 23-G PPV for the surgical removal of metallic posterior segment IOFBs.
\end{abstract}

Keywords: OTS, IOFB, Trauma, Pars plana vitrectomy, PPV

\section{Background}

Eyes represent only $0.27 \%$ of the body's surface area, but they are among the most common trauma-exposed areas and can present with severe morbidity [1]. Ocular trauma is a leading cause of monocular blindness and is an important public health problem [2].

The variablity in clinical characteristics is an inherent property of trauma patients. This variability in clinical characteristics in ocular trauma patients has led several investigators to study the factors that influence both anatomical success and final post-surgical visual acuity. The ocular trauma score (OTS) is a prognostic model developed by Kuhn et al. [3]. More than 2000 cases from the United States and Hungarian Eye Injury Registries were analyzed and $>100$ variables were evaluated to identify the

\footnotetext{
* Correspondence: dilekyasa2@gmail.com

Beyoğlu Eye Research and Training Hospital, Bereketzade Mah, Bereketzade Sok. No:2, Beyoğlu, İstanbul, Turkey
}

best predictors of outcome at 6 months after injury [3]. OTS has been widely used for this purpose in open and closed globe trauma $[4,5]$, however, only a few studies have evaluated the prognostic value of OTS in patients with retained intraocular foreign bodies (IOFBs) [6-8].

The purpose of this study was to evaluate prognostic OTS values in patients who underwent 23-gauge pars plana vitrectomy (23-G PPV) for removal of metallic IOFBs from the posterior segment of the eyes.

\section{Methods}

This study followed the tenets of the Declaration of Helsinki, and approval was obtained from institutional review board of Prof. Dr. N. Resat Belger Beyoglu Eye Training and Education Hospital. Medical records of patients who underwent 23-G PPV for surgical removal of retained IOFBs in the Beyoglu Eye Training and Education Hospital (BEH) during a 1-year period (January

(c) The Author(s). 2018 Open Access This article is distributed under the terms of the Creative Commons Attribution 4.0 International License (http://creativecommons.org/licenses/by/4.0/), which permits unrestricted use, distribution, and 
2016-January 2017) were retrospectively analyzed. Patients who had at least 6 months of follow-up were included in the study. Demographic data of the patients, zones of injury, types of IOFBs, associated ocular pathologies, time from trauma to PPV, follow-up time, and presenting and final visual acuities (VA) were obtained from the patients' records. Zones of injury were classified according to the Birmingham Eye Trauma Terminology System [9]. A zone I wound involves the cornea, a zone II wound extends into the anterior $5 \mathrm{~mm}$ of the sclera and a zone III wound involves the sclera extending more than $5 \mathrm{~mm}$ from limbus.

All VA examinations were performed with a back-illuminated Early Treatment Diabetic Retinopathy Study (ETDRS) chart. VAs were divided into five groups based on the OTS categories: 1.) no light perception; 2.) light perception/hand motions; 3.) $1 / 200$ to-19/200; 4.) $20 / 200$ to $<20 / 50$; or 5 .) $\geq 20 / 40$. The sum of each patient's raw points was calculated, and the numerical value was converted into the corresponding OTS score (shown in Tables 1 and 2) as described by Kuhn et al. [3]. Then, the similarity of final visual acuities by category was compared with those in the OTS study (Table 2).

\section{Surgical technique}

All eyes underwent standard 23-G PPV using the Constellation Surgical Vitrectomy System (Alcon Laboratories Inc., Fort Worth, TX, USA). Pars plana lensectomy or phacoemulsification was performed in eyes with lens opacity. In eyes with retinal detachment (RD), perfluorocarbon liquids were used to attach the retina, and retinal breaks were treated with endophotocoagulation. To remove the IOFBs, one of the sclerotomies were enlarged, and IOFBs were removed using intraocular forceps. Air, sulfur hexafluoride (SF6), perfluoropropane (C3F8), or $1000 \mathrm{cSt}$ silicone oil was used at the end of the surgery as an internal tamponade. Sclerotomies were sutured at

Table 1 Ocular Trauma Score (OTS)

\begin{tabular}{ll}
\hline Variables & Raw Points \\
\hline A. Initial Vision & 60 \\
NLP & 70 \\
LP/HM & 80 \\
$1 / 200-19 / 200$ & 90 \\
$20 / 200-20 / 50$ & 100 \\
$\geq 20 / 40$ & -23 \\
B. Rupture & -17 \\
C. Endophthalmitis & -14 \\
D. Perforating injury & -11 \\
E. Retinal detachment & -10 \\
F: Afferent pupillary defect &
\end{tabular}

NLP No light perception, LP Light perception, HM Hand motion the end of the surgery. In eyes with $\mathrm{RD}$, anatomical success was defined as total retinal attachment at the final visit.

\section{Statistical analysis}

Continuous data are presented as means and standard deviation while categorical data are presented as percentages. Chi square test was used for comparison of categorical distributions of final visual acuities and OTS scores between OTS study and our series. Mann-Whitney $U$ test was performed for the comparison of final visual acuities between the patients with and without RD. Additionally, Fisher's exact test was used to compare the categorical distribution of VAs in patients with and without RD. A two-tailed $p$-value $<0.05$ was considered statistically significant.

\section{Results}

Twenty-five eyes from 25 patients were included in the study. Twenty-four (96\%) of the patients were male, and the mean age was $34 \pm 12$ years (min:12, max: 64, median 37). The mean follow-up time was $10 \pm 5$ months (min: 6, max: 21, median 6). Presenting and final VAs of each patient are shown in Table 3. Cumulative VAs are presented in Fig. 1. At the final visit VA was 20/200, or better in $56 \%$ and $20 / 40$, or better in $28 \%$ of the eyes. Cumulative VAs in patients with or without a RD are shown in Table 4. Our hospital is a tertiary referral eye hospital and most of our patients are referred from rural areas of Turkey or from other hospitals. Accordingly, 7 (28\%) eyes had RD at presentation, and although anatomical success was achieved in 6 (85.7\%) of these, only $14.3 \%$ of the eyes had a final VA of $20 / 40$. Cumulative VAs were better in eyes without RD. However, the difference was not statistically significant (Table 4). Work-related trauma ( $96 \%$ of eyes) was the most common cause of the injury, which was followed by car accidents ( $4 \%$ of eyes). None of the patients was wearing protective safety glasses during trauma. Mechanism of injury are presented in Table 5.

There were $14(56 \%)$, eight (32\%), and three (12\%) cases of zones 1, 2, and 3, respectively. The mean time from injury to $23-\mathrm{G}$ PPV was $9 \pm 4$ days. Associated ocular pathologies are shown in Table 6 and injured intraocular structures are shown in Table 7. A metallic IOFB was found in all eyes. Posterior segment IOFBs were observed in $10(40 \%)$ eyes. In the remaining $4(16 \%)$ eyes, IOFB located in the vitreous cavity, $9(36 \%)$ in the peripheral retina, and $2(8 \%)$ nasal relative to the optic disc in the posterior pole of the eye. A total of $13(52 \%)$ eyes had cataract at the presentation. Of the 6 eyes with visually significant cataracts, 3 underwent pars plana lensectomy without intraocular implantation and 3 underwent phacoemulsification and intraocular lens implantation. 
Table 2 Comparison of final visual acuities and OTS categorical distributions between OTS study and our series

\begin{tabular}{llllllll}
\hline Sum of raw points & OTS & NLP & LP/HM & $1 / 200-19 / 200$ & $20 / 200-20 / 50$ & $\geq 20 / 40$ \\
& & A/B & A/B & A/B & A/B & A/B \\
\hline $0-44$ & 1 & $74 / 0$ & $15 / 0$ & $7 / 100$ & $3 / 0$ & $1 / 0$ & 0.116 \\
$45-65$ & 2 & $27 / 7$ & $26 / 50$ & $18 / 14$ & $31 / 50$ & 0.195 \\
$66-80$ & 3 & $2 / 0$ & $11 / 0$ & $15 / 0$ & $22 / 33$ & $41 / 50$ \\
$81-91$ & 4 & $1 / 0$ & $2 / 0$ & $3 / 0$ & $57 / 0$ & $73 / 67$ & 0.856 \\
$92-100$ & 5 & $0 / 0$ & $1 / 0$ & $1 / 0$ & $94 / 0$ & N/A \\
\hline
\end{tabular}

OTS Ocular Trauma Score, NLP No light perception, LP light perception, HM Hand motion, $A$ OTS Study results (\%), $B$ Our study results (\%)

${ }^{a}$ Chi-square test

One eye with pars plana vitrectomy underwent intraocular lens placement with scleral fixation 6 months after the first surgery. In the remaining 2 eyes, lens placement was not considered because of the poor visual prognosis. All IOFBs were successfully removed, and anatomical success was achieved at the final visit in $96 \%$ of 25 eyes with or without RD at presentation.

Table 3 Presenting and final visual acuities and OTS of individual patients

\begin{tabular}{|c|c|c|c|c|c|c|}
\hline No & Age & Gender & OTS & OTS Category & VA (admission) & VA (final) \\
\hline 1 & $40-50$ & Male & 28 & 1 & $L P$ & $20 / 1500$ \\
\hline 2 & $40-50$ & Male & 56 & 2 & $\mathrm{HM}$ & $20 / 100$ \\
\hline 3 & $40-50$ & Male & 56 & 2 & $\mathrm{HM}$ & $\mathrm{HM}$ \\
\hline 4 & $20-30$ & Male & 56 & 2 & $\mathrm{HM}$ & $20 / 1500$ \\
\hline 5 & $60-70$ & Male & 56 & 2 & $L P$ & $\mathrm{HM}$ \\
\hline 6 & $20-30$ & Male & 56 & 2 & $L P$ & $20 / 400$ \\
\hline 7 & $10-20$ & Male & 56 & 2 & $L P$ & $\mathrm{HM}$ \\
\hline 8 & $30-40$ & Male & 56 & 2 & $L P$ & $\mathrm{HM}$ \\
\hline 9 & $30-40$ & Male & 56 & 2 & $L P$ & $\mathrm{HM}$ \\
\hline 10 & $30-40$ & Male & 65 & 2 & $20 / 50$ & $20 / 32$ \\
\hline 11 & $30-40$ & Male & 45 & 2 & $\mathrm{HM}$ & $\mathrm{HM}$ \\
\hline 12 & $10-20$ & Female & 45 & 2 & $\mathrm{HM}$ & $\mathrm{HM}$ \\
\hline 13 & $40-50$ & Male & 45 & 2 & $L P$ & $20 / 200$ \\
\hline 14 & $30-40$ & Male & 55 & 2 & $5 / 200$ & $20 / 100$ \\
\hline 15 & $10-20$ & Male & 45 & 2 & $L P$ & NLP \\
\hline 16 & $40-50$ & Male & 76 & 3 & $20 / 63$ & $20 / 200$ \\
\hline 17 & $10-20$ & Male & 76 & 3 & 0.16 & $20 / 20$ \\
\hline 18 & $30-40$ & Male & 76 & 3 & $20 / 50$ & $20 / 200$ \\
\hline 19 & $40-50$ & Male & 76 & 3 & $20 / 50$ & $20 / 32$ \\
\hline 20 & $20-30$ & Male & 86 & 4 & $20 / 32$ & $20 / 63$ \\
\hline 21 & $30-40$ & Male & 86 & 4 & $20 / 40$ & $20 / 32$ \\
\hline 22 & $40-50$ & Male & 86 & 4 & $20 / 25$ & $20 / 25$ \\
\hline 23 & $20-30$ & Male & 86 & 4 & $20 / 20$ & $20 / 20$ \\
\hline 24 & $30-40$ & Male & 86 & 4 & $20 / 20$ & $20 / 20$ \\
\hline 25 & $20-30$ & Male & 86 & 4 & $20 / 32$ & $20 / 63$ \\
\hline
\end{tabular}

OTS Ocular trauma score, VA Visual acuity (Snellen), LP Light perception, NLP No light perception, $H M$ Hand motion
The most common postoperative complication was an increase in intraocular pressure (12\%), but it was controlled with medical treatment in all patients. One eye with RD at baseline had macula-off RD and no light perception at the final visit. In one patient, who had a culture that was negative for endophthalmitis at presentation, recurrent RD occurred, but anatomical success was achieved after the second 23-G PPV. Air was used as an internal tamponade in $8(32 \%)$ eyes, SF6 in $2(8 \%)$ eyes, C3F8 in $3(12 \%)$ eyes, and silicone oil in $12(48 \%)$ eyes. One eye with $\mathrm{RD}$ at the presentation treated with PPV and silicone oil injection and 1 eye without RD treated with PPV and C3F8 injection showed RD during follow-up. They underwent second PPV to achieve retinal reattachment. At the final visit, retina was still attached in those 2 patients. Silicone oil was removed in 12 eyes in the mean time of 5.7 months after PPV. In the remained one eye with cyclodialysis at the presentation, silicone oil was not removed because of the chronic hypotonia. Final VAs based on OTS categories and the OTS scores are presented in Table 2.

All patients were administered systemic antibiotics (moxifloxacin) until IOFB removal with PPV. Only 3 patients were given intravitreal antibiotics (vancomycin and ceftazidime), solely based on surgeon preference, not signs of endophthalmitis. Topical antibiotics were applied as an appropriate adjuvant to intravitreal and systemic antibiotic use once the wound was closed following PPV.

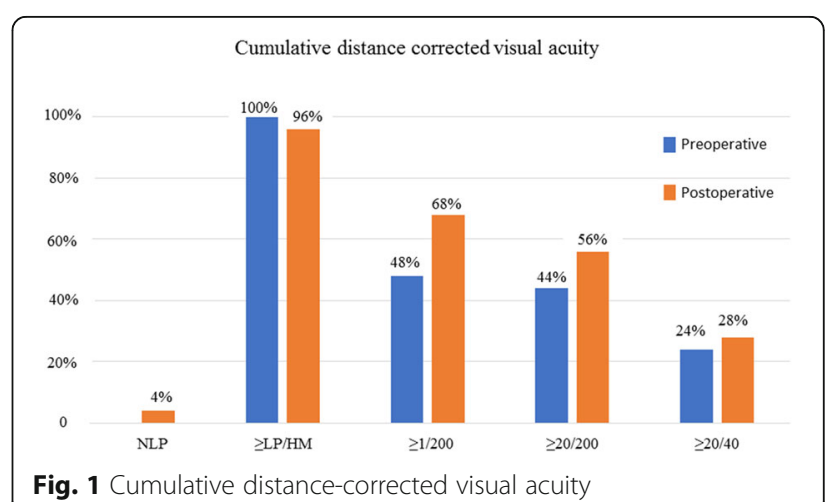


Table 4 Visual acuities in eyes with and without retinal detachment

\begin{tabular}{llll}
\hline & $\begin{array}{l}\text { Eyes with RD } \\
n=7\end{array}$ & $\begin{array}{l}\text { Eyes without RD } \\
n=18\end{array}$ & $p$ \\
\hline VA (Mean \pm SD, logMAR) & $1.64 \pm 1.24$ & $1.26 \pm 1.27$ & $0.398^{*}$ \\
VA $\geq$ LP/HM (\%) & 85.7 & 100 & $0.280^{* *}$ \\
VA $\geq 1 / 200(\%)$ & 57.1 & 72.7 & $0.640^{* *}$ \\
VA $\geq 20 / 200(\%)$ & 42.9 & 61.1 & $0.656^{* *}$ \\
VA $\geq 20 / 40(\%)$ & 14.3 & 33.3 & $0.626^{* *}$
\end{tabular}

HM Hand motions, LP Light perception, $n$ Number of eyes, SD Standard deviation, $R D$ Retinal detachment, $V A$ Visual acuity

*: Mann Whitney U test, two-tailed $p$ value

**: Fisher's Exact Test, two tailed $p$ value

\section{Discussion}

IOFBs may be associated with up to $40 \%$ of open globe injuries especially with respect to work related injuries $[10,11]$. Male dominance and the peak patient age in the young to middle-aged group in our study was in agreement with reports in the literature in which young to middle-aged working males are at the highest risk for ocular trauma.

Greven et al. reported final VAs of 20/40 of more were obtained in 71\% of IOFB-associated open globe injuries [12]. Although their results are superior to those associated with the general functional outcomes in other types of open globe trauma, other investigators have reported that functional success is not more common in eyes with IOFB [4]. Ahmadieh et al. [13] found that IOFB was a poor predictor of visual outcome. These conflicting findings probably result from the fact that the patients with IOFB are a heterogeneous group with different clinical characteristics that are dependent on the nature of the injury and the foreign body.

Anatomical and visual outcomes, as well as postoperative complications in this study were comparable to those reported in the literature [4-6]. The final visual acuity of eyes with $\mathrm{RD}$ was lower when compared to eyes without a RD. However, it did not reach the level of statistical significance. The reason for the lack of statistically significant difference between the groups (eyes with $\mathrm{RD}$ and eyes without RD) may be the low number of patients (only seven patients had RD), the complex nature of trauma, heterogeneity of this patient group, and other factors limiting functional success in patients who do not have RD at presentation.

Table 5 Mechanism of injury

\begin{tabular}{lc}
\hline & $\mathrm{n}(\%)$ \\
\hline Hammering & $11(44)$ \\
Chisseling & $3(12)$ \\
Drilling & $4(16)$ \\
Cutting metal & $6(24)$ \\
Car crash & $1(4)$ \\
\hline
\end{tabular}

$n$ Number of eyes
Table 6 Associated ocular pathologies

\begin{tabular}{ll}
\hline Ocular Pathology & $\mathrm{n}(\%)$ \\
\hline Cyclodialysis & $3(12)$ \\
Iridodialysis & $1(4)$ \\
Traumatic Cataract & $13(52)$ \\
Intravitreal hemorrhage & $8(32)$ \\
Choroidal detachment & $1(4)$ \\
Retinal detachment & $7(28)$ \\
Endophtalmitis & $1(4)$ \\
\hline$n$ Number of eyes &
\end{tabular}

$n$ Number of eyes

OTS has been widely in open and closed globe trauma $[4,5,13-15]$. However, it had been validated in only a few subgroups of patients with IOFBs. Unal et al. [6] reported the prognostic value of OTS in cases of deadly weapon-related open-globe injuries with IOFB, Purtskhvanidze et al. [7] in rotating wire brush injuries with IOFB, and Zhu et al. [8] in siderosis bulbi with retained IOFB. Although all of them were associated with IOFBs, the mechanism of injury, presenting clinical characteristics, and distribution of OTS scores were very different among these studies. On one hand, $40 \%$ of the patients in the Purtskhvanidze et al. [7] study were OTS 5, whereas none of the patients in the Unal et al. [6] study were OTS 5. Results from Unal et al. [6] were similar to those in this OTS study, except for OTS category 2; results from Purtskhvanidze et al. [7] were similar to those in this OTS study, except for OTS category 1. Results from the study by Zhu et al. [8] were similar to those in this OTS study in all categories.

Our study group was different from the others in the literature in that we only included cases of metallic posterior segment IOFBs that required PPV. However, we obtained similar results and showed that OTS can successfully predict the functional outcome after successful removal of the IOFB with 23-G PPV. We had no patient in OTS category 5 , but the final VAs were similar to the OTS categories.

One limitation of our study was the low number of patients and retrospective study design. Also, we evaluated

Table 7 Injured intraocular structures

\begin{tabular}{ll}
\hline Zone 1 & $\mathrm{n}(\%)$ \\
Zone 2 & $14(56)$ \\
Zone 3 & $8(32)$ \\
Iris/ciliary body & $3(12)$ \\
Crystalline lens & $4(16)$ \\
Macula & $13(52)$ \\
Peripheric retina & $2(8)$ \\
Sclera & $9(36)$ \\
\hline$n$ Number of eyes & $11(44)$ \\
\hline
\end{tabular}

$n$ Number of eyes 
pediatric and adult patients together due to the low number of patients. In addition, there may be a geographical bias that is inherent to trauma studies. This fact underlies the need for a National Eye Registry and multicenter studies for trauma patients in Turkey. However, the relatively homogeneous patient group in this study showed that OTS was useful for this special subgroup of IOFB.

\section{Conclusions}

In conclusion, we found that OTS, which provides prognostic information after general ocular trauma, may also provide reliable prognostic information on patients who undergo 23-G PPV for the surgical removal of metallic posterior segment IOFBs. OTS may offer the possibility of approximation of the functional result in these patients before the surgery.

\section{Abbreviations}

23 G PPV: 23-gauge pars plana vitrectomy; C3F8: Perfluoropropane:

HM: Hand motion; IOFB: Intraocular foreign body; IOP: Intraocular pressure; LP: Light perception; OTS: Ocular trauma score; PPL: Pars plana lensectomy;

RD: Retinal detachment; SF6: Sulfur hexafluoride; VA: Visual acuity

\section{Funding}

The authors declare that no funding was received.

\section{Availability of data and materials}

The datasets used and/or analysed during the current study are available from the corresponding author on reasonable request.

\section{Authors' contributions}

Involved in conceptualization of the manuscript and design of the study (DY, ZTA, AD,); acquisition, analysis and interpretation of data of data (ZGE, GD); drafting the manuscript (ZGE, GD); critical review and revision of the manuscript for important intellectual content (DY, ZTA, AD). All authors read and approved the final manuscript.

\section{Ethics approval and consent to participate}

All procedures performed in studies involving human participants were in accordance with the ethical standards of the institutional and/or national research committee and with the 1964 Helsinki declaration and its later amendments or comparable ethical standards. This study was approved by the institutional review board of Prof. Dr. N. Reşat Belger Beyoglu Göz Eğitim ve Araşıırma Hastanesi (Prof. Dr. N. Reşat Belger Beyoglu Eye Training and Education Hospital). Consent forms were obtained from all of the patients before each treatment applied in the study. Parental consent was obtained for patients under the age of 16

\section{Consent for publication}

For this type of study formal consent is not required.

\section{Competing interests}

The authors declare that they have no competing interests.

\section{Publisher's Note}

Springer Nature remains neutral with regard to jurisdictional claims in published maps and institutional affiliations.

Received: 4 March 2018 Accepted: 3 August 2018

Published online: 09 August 2018

\section{References}

1. Nordber E. Injuries as a public health problem in sub-Saharan Africa: epidemiology and prospects for control. East Afr Med J. 2000;77:1-43.
2. Negrel AD, Thylefors B. The global impact of eye injuries. Ophthalmic Epidemiol. 1998:5:143-69.

3. Kuhn F, Maisiak R, Mann L, Mester V, Morris R, Witherspoon CD. The ocular trauma score (OTS). Ophthalmol Clin N Am. 2002:15:163-5. vi

4. Ünver YB, Kapran Z, Acar N, Altan T. Ocular trauma score in open-globe injuries. J Trauma. 2009:66:1030-2.

5. Serdarevic R. The ocular trauma score as a method for the prognostic assessment of visual acuity in patients with close eye injuries. Acta Inform Med. 2015:23:81-5.

6. Unal MH, Aydin A, Sonmez M, Ayata A, Ersanli D. Validation of the ocular trauma score for intraocular foreign bodies in deadly weapon-related openglobe injuries. Ophthalmic Surg Lasers Imaging. 2008;39:121-4.

7. Purtskhvanidze K, Rüfer F, Klettner A, Borzikowsky C, Roider J. Ocular trauma score as prognostic value in traumatic ocular injuries due to rotating wire brushes. Graefes Arch Clin Exp Ophthalmol. 2017;255:1037-42.

8. Zhu L, Shen P, Lu H, Du C, Shen J, Gu Y. Ocular trauma score in Siderosis bulbi with retained intraocular foreign body. Medicine (Baltimore). 2015;94(39):e1533.

9. Kuhn F, Morris R, Witherspoon CD, Heimann K, Jeffers JB, Treister G. A standardized classification of ocular trauma. Ophthalmology. 1996;103:240-3.

10. Palioura S, Eliott D. Traumatic endophthalmitis, retinal detachment, and metallosis after intraocular foreign body injuries. Int Ophthalmol Clin. 2013:53:93-104

11. Kıvanç SA, Akova Budak B, Skrijelj E, Tok ÇM. Demographic characteristics and clinical outcome of work-related open globe injuries in the most industrialised region of Turkey. Turk J Ophthalmol. 2017;47:18-23.

12. Greven CM, Engelbrecht NE, Slusher MM, Nagy SS. Intraocular foreign bodies: management, prognostic factors, and visual outcomes. Ophthalmology. 2000;107:608-12

13. Ahmadieh H, Soheilian M, Sajjadi H, Azarmina M, Abrishami M. Vitrectomy in ocular trauma. Factors influencing final visual outcome. Retina. 1993;13:107-13.

14. Shah MA, Agrawal R, Teoh R, Shah SM, Patel K, Gupta S, Gosai S. Pediatric ocular trauma score as a prognostic tool in the management of pediatric traumatic cataracts. Graefes Arch Clin Exp Ophthalmol. 2017:255:1027-36.

15. Kutlutürk Karagöz I, Söğütlü Sarı E, Kubaloğlu A, Elbay A, Çallı Ü, Pinero DP, Özertürk Y, Yazıcıoğlu T. Characteristics of pediatric and adult cases with open globe injury and factors affecting visual outcomes: a retrospective analysis of 294 cases from Turkey. Ulus Travma Acil Cerrahi Derg. 2018;24:31-8.

Ready to submit your research? Choose BMC and benefit from:

- fast, convenient online submission

- thorough peer review by experienced researchers in your field

- rapid publication on acceptance

- support for research data, including large and complex data types

- gold Open Access which fosters wider collaboration and increased citations

- maximum visibility for your research: over $100 \mathrm{M}$ website views per year

At BMC, research is always in progress.

Learn more biomedcentral.com/submissions 